\title{
Medialidad, movimiento y paradoja temporal en la escritura de Ronald Kay
}

\section{Mediality, Movement and Temporal Paradox in the Writings of Ronald Kay}

Valeria de los Ríos

Instituto de Estética, Pontificia Universidad Católica de Chile.

edelo@uc.cl

\section{Resumen}

En este artículo me propongo explorar la centralidad de los medios -particularmente la fotografía, aunque también el cine y la televisión- en el pensamiento y la escritura de Kay, a partir de la lectura atenta de los poemarios Variaciones ornamentales y Deep Freeze, así como también de sus ensayos Del espacio de acá y Circuito cerrado. En estas obras Kay reflexiona en torno al carácter medial de las técnicas y los aparatos, así como también acerca de las transformaciones que generan los medios en otros medios (intermedialidad) y sus consecuencias sobre las dimensiones espaciotemporales y el movimiento.

Palabras clave: Ronald Kay, Fotografía, Escritura, Medialidad, Temporalidad.

\section{Abstract}

In this article I intend to explore the centrality of the media - particularly photography, but also film and television - in Ronald Kay's thinking and writing, starting from a close reading of the poems of Variaciones Ornamentales and Deep Freeze, as well as his essays Del espacio de acá and Circuito cerrado. In these works, Kay reflects on the medial nature of techniques and devices, as well as on the transformations that media generates in other media (intermediality) and its consequences on spatio-temporal dimensions and on movement.

Keywords: Ronald Kay, Photography, Writing, Mediality, Temporality. 
En el boletín N² del Centro de Estudios de Artes dedicado a Ronald Kay, publicado en octubre de 2017, Justo Pastor Mellado señala que Kay “dibujó un mapa crítico nuevo, que no ha sabido ser leído por los agentes de análisis literario de la última década” (11). Mellado sostiene que la reedición del El Quebrantahuesos ${ }^{1}$, gracias al trabajo editorial de Kay en la revista Manuscritos del Departamento de Estudios Humanísticos de la Universidad de Chile en 1975, tiene una carácter fundacional tanto para una nueva escena de artes visuales, como de la poesía chilena (10). En este artículo me propongo explorar este gesto fundacional a través de la lectura atenta y el análisis de la escritura de Kay en dos de sus textos más emblemáticos: Variaciones Ornamentales (Made in Germany) (1979) y Del espacio de acá. Señales para una mirada americana (1980), en los que se hace evidente una reflexión sobre los ejes de la medialidad y temporalidad a partir de la fotografía. Para ello recurriré a otros textos de Kay que arrojan luces sobre los procedimientos involucrados en la escritura de Variaciones Ornamentales, como Circuito Cerrado (2001) o Deep Freeze (2000), que enuncia desde su título y su portada la paradoja de la imagen en movimiento.

El gesto fundacional de Kay radicaría en dar cuenta en el contexto chileno de fines de los años 60 y principios de los años 70 de cierta ruptura de la estética moderna que Jacques Ranciére reconoce como el surgimiento del régimen estético de las artes. Según Ranciére este régimen no estaría caracterizado como el paso de un régimen de representación a uno de la presencia o presentación (autonomía del arte o sublimidad), sino más bien como la coexistencia de dos regímenes de expresión que se encuentran entrelazados sin una relación definida (118). Estos regímenes de expresión serían, en el caso de Kay, el de la escritura y el de la imagen técnica.

Ranciére habla de la "pensatividad de la imagen" que surge ante la presencia latente de un régimen de expresión dentro de otro (121) y señala un "proceso de impersonalización”, que puede formularse como la invasión de la acción literaria por la pasividad de la imagen (120). En este caso, lo visual que suscita la frase no es ya un complemento de la expresividad, sino un elemento de la construcción de otra cadena narrativa, "un encadenamiento de acontecimientos sensibles que vienen a duplicar el encadenamiento clásico de las causas y los efectos, de los fines proyectados, de sus realizaciones y sus consecuencias" (120). Esto que Ranciére enuncia reflexivamente en su libro El espectador emancipado del 2008, Kay lo trabaja poética y materialmente en Variaciones ornamentales (1979) y crítica y materialmente en Del espacio de acá (1980). Para Kay la fotografía como imagen técnica mediatiza la escritura, pero también la pintura y la autorrepresentación de los aborígenes en el continente americano, de allí su centralidad en este particular lugar de enunciación.

1 El Quebrantahuesos fue una intervención poética colectiva, de carácter vanguardista, realizada por Nicanor Parra, Alejandro Jodorowsky y Enrique Lihn en 1952. Se trató de la creación y exhibición de textos construidos a partir de recortes de diarios, exhibidos en el espacio público, en lugares como los Tribunales de Justicia, el restaurante El Naturista y la calle Bandera. 
La llegada de la fotografía a Latinoamérica ocurrió en un momento particular de la historia del continente, cuando la mayoría de los países cumplía las primeras décadas de vida independiente, luego de los procesos de autonomización. Tal como lo afirma Kay en Del espacio de acá, esta llegada produjo una discontinuidad temporal, provocada por la superposición de al menos dos temporalidades históricas diferentes: primero, el tiempo de la máquina en el contexto metropolitano en que fue creada, y segundo, el tiempo de las ex colonias, en las que este aparato se insertó. Según Kay, hacia 1850 la cámara penetró en el espacio americano, incorporando a sus negativos sujetos y objetos prefotográficos. Por la naturaleza citable de la fotografía, en este proceso se tocan dos tiempos discontinuos. En palabras de Kay se trata de varios tiempos y una sola imagen, por tanto, el resultado es una imagen estratificada y una discronía.

La fotografía tiene para Kay un sentido material, de allí que muchas de las metáforas que utiliza para referirse a ella -por ejemplo, la "estratificación"- sean geológicas. La fotografía opera como una superficie en la que conviven y se tocan objetos pertenecientes a distintas épocas, y posee una temporalidad que se le adhiere a partir del aparato que la hace posible. Esto permite que en un solo objeto estratificado convivan varias temporalidades.

De este modo, la fotografía funcionó como un acto de posesión, que "tomó" literalmente la imagen del continente. En el pensamiento de Kay este acto de ocupación ocurrió en parte porque en el contexto latinoamericano no existía una tradición pictórica consolidada, por lo que la máquina fotográfica usurpó la posibilidad de que el continente se creara una imagen propia. Más allá de la comprobación de esta tesis avezada respecto a la tradición de la pintura, me interesa la centralidad de la fotografía en el pensamiento y la escritura de Kay, que la concibe como un objeto que mediatiza tanto la pintura como la escritura.

Kay publica Del espacio de acá en 1980, el mismo año en que Roland Barthes edita en París La cámara lucida. Tres años antes, Susan Sontag había publicado Sobre la fotografía en Estados Unidos. El otro antecedente era por supuesto, el trabajo de Walter Benjamin, a cuya lectura Kay introdujo a muchos durante los años 70. Kay se aventura con una interpretación epistémica de la fotografía, que mediatiza otros soportes porque es capaz de cambiar nuestra noción de la historia y la temporalidad, y da cuenta de esta transformación radical incluso antes de que Vilém Flusser publicara Para una filosofía de la fotografía (1983), y Nelly Richard editara Márgenes e instituciones (1986).

Según Kay, la fotografía retarda el tiempo hasta su detenimiento y con ello pone al hombre en nuevas dimensiones espacio-temporales. La imagen se emancipa del orden de las cosas y los seres, convirtiéndose en una huella óptica, aparte y autónoma, En Del espacio de acá Kay escribe:

En las intemperies de las perturbadas superficies fotosensibles se exhibe el parto cruel de una imagen, contenida ya no en la contingencia de los sucesos, sino fija y libre en la huella óptica, aparte y autónoma. Este desprendimiento aniquila la 
primacía de los objetos en la visualidad; aniquilamiento que toda foto muestra como su revés: el espectáculo trágico del abandono de la vida, infuso en ellas como un cuadro paranoico en otro cuadro. (20)

Más allá de capturar el flujo vital -según Kay- ahorrándolo detenido para los archivos de la memoria, la pupila del lente violenta lo visto, traspasa su tiempo pasajero y caduco, llegando a otro artificial, al presente infinito y sintético:

El enfoque del ojo técnico hunde las estatuas en blanco y negro (o en tecnicolor), con todo lo que ellas encarnan, en la cronología arrestada, siempre igual y repetible del automatismo; las arranca del olvido orgánico, para hacerlas reaparecer mudas y dobladas en la superficie estable de la instantánea. (Del espacio de acá 20-21)

Se trata aquí de un "silencio químico", que drena el ruido y sustrae el oído de lo fotografiado. Así, la voz y el instante quedan asociados en la presencia, mientras que el silencio y la detención de la temporalidad aparecen unidos en el objeto fotográfico. Tal como lo establece Barthes en relación a la pose, para Kay la fotografía aparece como una piel suplementaria y el verse retratado equivale a observar un producto "Elisabeth [sic] Arden de Thanatos", una máscara mortuoria de la civilización. En el acto fotográfico, se produce un proceso de materialización que fija gestos que son automáticos incluso antes de la aparición de la cámara. Kay lo describe así:

El mecanismo del disparador de la cámara es la exteriorización y materialización de un tic, una metáfora mecánica de un acto compulsivo de repetición. Al disparar el obturador, este automatismo ampliado, autónomo y cosificado se vuelve a inscribir en la fotogenia de nuestro cuerpo. Se captan y formalizan los automatismos inconscientes. Se hace visible la escritura automática de los gestos. (Del espacio de acá 22-23)

El resultado de este proceso es una división de la temporalidad que inscribe en la fotografía los gestos de los cuerpos. Según Kay, en el momento de la toma ocurre una traducción, un traslado o transporte material de lo registrado fotográficamente. Pero este traslado provoca también una sincronicidad temporal y una objetivación -una reificación, podría decirse- ya que el tiempo -por definición efímero- se congela en la fotografía, y así el tiempo del instante y el tiempo eternizable se hacen citables, equivalentes. Esto facilita su reproductibilidad y su posibilidad de convertirse en archivo. Kay escribe:

La súbita y fáctica escisión del núcleo temporal en su traslado fotográfico produce y construye una sincronía. Por la sincronía son puestos en un mismo plano dos órdenes temporales: el de lo único, fungible y contingente, y el de los interminable que se conserva y "eterniza" en la foto, difiriendo su efecto y repercusión. En la fotografía, ambos órdenes entran en una relación recíproca de 
cita y pasan a ser citables: lo transitorio está en su trascripción y lo permanente pasa a ser técnicamente reproducible y citable y combinable. Esta es la cualidad documental de la huella óptica (Del espacio de acá 25).

Pero quizás más que el registro de un evento mediante una huella óptica, -lo que según Barthes le daría a la fotografía su noema; el "haber-estado alli" - la fotografía es para Kay "la invisible inscripción material de la mirada de un testigo potencial" (23). Aquí Kay se distancia de Benjamin y en lugar de poner el acento en la fotografía como prueba, lo pone en el observador, tal como lo hace Ranciére en El espectador emancipado.

En "Pequeña historia de la fotografía", al hablar de la producción fotográfica de Eugene Atget como "la escena del crimen”, Benjamin se pregunta: “PPero no es cada rincón de nuestras ciudades un lugar del crimen? ¿no es un criminal cada transeúnte? ¿no debe el fotógrafo - descendiente del augur y del arúspice- descubrir la culpa en sus imágenes y señalar al culpable?" (82). Asimismo, en "París del Segundo Imperio en Baudelaire", Benjamin afirma que la invención de la fotografía fue esencial para los detectives: "Para la criminalística significa no menos de lo que la invención de la imprenta para la escritura. La fotografía hace posible, por primera vez, retener por mucho tiempo claras huellas de una persona." (114). Esta condición de la fotografía da la posibilidad de estar simultáneamente en la mirada y fuera de la mirada, sin abandonar lo visible. Kay escribe: "En esta perspectiva aparece el ojo fotográfico como crítica a la mirada física: aquí reside su fuerza revolucionaria" (25). Esta fuerza revolucionaria de la fotografía hace factible que su impacto vaya más allá de la fotografía en sí misma y se haga presente en las pinturas aeropostales de Eugenio Dittborn, o en su propia escritura poética.

En 1979, o sea un año antes de Del espacio de acá, Kay había publicado Variaciones ornamentales (1979), un poemario escrito entre 1969 y 1972 durante su estadía en Konstanz (Alemania), en el que Kay empieza a delinear su pensamiento sobre la fotografía o su escritura fotográfica. Tal como nota Mellado en su artículo "El diagrama de constructividad editorial en Ronald Kay" la sección titulada "El tiempo que se divide" de Del espacio de acá "es contemporánea de la escritura de los materiales que conformarán Variaciones ornamentales" (22). En Circuito cerrado, una especie de prólogo explicativo para la publicación tardía de los inéditos de la década del 60, Kay señala algunos elementos de su poética, que incluye la "reticencia a hacer público lo escrito" por un interés de "desligar lo escrito de la presencia carnal" 2 de modo que "retirarse de la actualidad es la consecuencia de una estrategia poética" (7). Para Kay

2 En la segunda sección de Circuito cerrado Kay señala que la idea de publicar sus inéditos responde a la necesidad de "incluir en la propia historia la ausencia; de adentrarse en lo fantasmático de ella, de exponer lo irreal como virtud" (9). Algo similar ocurre en la escritura de Enrique Lihn, contemporánea a la de Kay, tal como lo evidencio en mi ensayo Fantasmas artificiales. Cine y fotografía en la escritura de Enrique Lihn (Santiago: Hueders, 2015). 
la escritura -al igual que otras formas de mediación, como la fotografía- produce automáticamente un espacio de virtualidad: "Automáticamente todo verso se conecta con el tiempo de la tradición, el de los muertos, y se proyecta al de los por nacer. [...] Quien lo escribe, ubica sus tejidos y su pulso en un espacio no exclusivamente lindante con el hoy" (9) [cursivas en el original]. De este modo, la medialidad, intrínseca a toda escritura, supone un trastocamiento de la temporalidad que se actualiza en la lectura. Un ejemplo de esto, es el carácter premonitorio de la escritura poética, que Kay enuncia en una nota de Circuito cerrado en la que se refiere a Variaciones ornamentales: "los poemas parecen estar escritos después del Golpe, siendo que lo fueron antes. Esta cualidad premonitoria -registrar en el presente como existente el estado futuro-tan manifiesta en ellos, le es inherente a toda poesía, el mántico auscultar de los hechos" (10) [cursivas en el original].

En su escritura, Kay quiere desligarse de poetas monumentales como Victor Hugo o Neruda -a quienes llama "pontificias personificaciones del hablante lírico" (7)-, pero también se diferencia de otros poetas como Juan Luis Martínez y Raúl Zurita, ya que según indica en una nota al pie de página de Circuito cerrado, La Nueva Novela y Purgatorio,

[...] son libros que se juegan en el ámbito de la cultura y de la metafísica: las innúmeras referencias eruditas, en el primero, y las plurales alusiones a Dios, en el segundo, denotan a un sujeto que toma una posición dentro de un ámbito exterior a él, que lo supera, y que se refiere a éste como algo consabido. (26)

En Circuito cerrado Kay relata algunos antecedentes de circulación de la obra y su impacto entre escritores y artistas en el contexto de la dictadura:

Habiendo circulado privadamente con anterioridad como tiposcrito entre las amistades que se quedaron-Parra, Lihn, Martínez, Zurita, y la Catalina, Dittborn, Leppe, Dávila- las Variaciones ya habían repercutido sea en sus escritos, sea en sus cuadros. En la desertificación de los días uniformados ayudaron a irrigar dicho oasis de irreprimibles poetas y pintores, a extender el número inmune de almas" (20) [cursivas en el original]

Sin embargo, el impacto público de las Variaciones ornamentales fue limitado, en parte por lo que Kay llama el "desinterés interesado" de la crítica, como por la aparición consiguiente de Del espacio de acá, que "acaparando la atención, eclipsó la exigua suma de poemas, aunque ella sea el fundamento de ese espacio" (Circuito cerrado 21) [cursivas en el original]. Es esta centralidad de Variaciones ornamentales la que analizaré aquí, junto con su entrelazamiento con otros escritos del propio Kay.

La portada del volumen incluye una fotografía tomada directamente de la televisión, de la película Saigon (1948) dirigida por Leslie Fenton, un film-noir protagonizado por Veronica Lake y Allan Ladd, que según indica Mellado, fue "emitido en el seno de una programación de la televisión chilena, a fines de la década del 70’ (7). 
$\mathrm{Al}$ interior del volumen se encuentran otras fotografías - un total de ocho- tomadas de la pantalla de la misma película, lo que evidencia el carácter mediatizado de la escritura, en otras palabras, su carácter intermedial. La imagen en sí misma está mediada, porque no se trata de un fotograma, sino de una fotografía tomada del televisor, con sus bordes y las líneas que surgen de los rayos catódicos, identificándola así como perteneciente a ese medio en particular. A esto hay que agregar el carácter serigráfico de la impresión, tal como ha notado Mellado al identificar el grano grueso que constituye la trama de la imagen reproducida (9). El libro contiene un diagrama de "doble registro visual/textual" (Mellado 11), que daría cuenta de la coexistencia de dos regímenes de representación, tal como lo señalara Ranciére. Desde un punto de vista más contextual, Kay da cuenta de esta naturaleza mediada de los poemas de Variaciones ornamentales en relación al fortalecimiento del rol de los medios masivos en el contexto de la Unidad Popular:

La lucha por el poder ocurría, más que en las calles y en la loca geografía, en los medios: ¿quiénes serán definitivamente aquellos que proveerán y sustentarán la imagen y el sonido y la máxima justos?

La naturaleza medial -el enviroment de las técnicas de reproducción-configura el sentido de nuestra actual percepción y en definitiva, es la percepción. No es un trasfondo, sino el interior desde el cual el destino se decide nuestro. (22) [cursivas en el original]

La pregunta por los medios y la convicción de su centralidad no solo para el contexto de las luchas revolucionarias, sino que para toda forma de percepción, es muy cercano en Kay al dictum de Friedrich Kittler "los medios determinan nuestra situación" (XXXIX). Kay señala:

Apartarse, en la búsqueda de la certeza poética, del supuesto realismo de los hechos significó adentrarse en las precisiones del microsurco, del nitrato de plata $y$ de las ondas electromagnéticas.

El breviario de las Variaciones ornamentales da cuenta y define esa sinestesia medial (22). [cursivas en el original]

En ese sentido, resulta casi una consecuencia evidente que los poemas de Variaciones ornamentales se refieran abiertamente a problemas visuales. El poema que abre el libro se titula "Alta visibilidad" y el segundo, "No encontró su imagen en el espejo" y pareciera aludir a los personajes de la película de la portada y del interior del libro:

Originalmente la heroína del poema

se podía ver admirando la acción de una máquina de lavar.

Se prefirió que ella figurara

como sujeto tácito de una oración negativa simple,

para demostrar que los representantes del sexo femenino 
pueden cumplir con otro orden de funciones.

En una escala mayor, en traje de sastre de un tweed

sal y pimienta. En la actitud de dar la espalda

al cadáver del hombre que acaba de matar,

hubiera sido todavía el foco de atención

de las generaciones futuras. Rasgos distintivos

de este discurso son la reiterada referencia

a procedimientos fotográficos y el uso único

de la palabra carne: ambos implican

una conección [sic] con el mundo fuera del poema. (2)

El hablante en el poema se ubica en un lugar intersticial, entre el mundo referencial ("el mundo fuera del poema") y la representación (en la imagen y en la escritura). Aparece, así como una especie de observador que al enunciar, organiza la escena. Sin embargo, se mantiene distanciado e impersonal, alejado de la primera persona singular y concentrado en la heroína, a quien pone y saca de los roles de género tradicionales, hasta hacerla figurar finalmente como una femme fatal asesina, vestida de tweed. La mención de los procedimientos fotográficos y el uso de la palabra "carne" entregan claves sobre las paradojas que abren los procedimientos visuales involucrados en la escritura del libro. En Circuito cerrado, en un apartado titulado "Rewriting" Kay señala de manera explícita:

En las Variaciones el lenguaje escrito es, por decirlo metafóricamente, fotografiado: así, convocado anónimamente -out of nowhere-expone y documenta la mente mediatizada y, subliminalmente en su lectura concita el dolor institucional que el individuo encarnará si ha de subsistir como sujeto frente a lo leído. (23) [cursivas en el original]

Los poemas del libro son breves y se distribuyen numerados por números romanos, uno por cada página. El estilo es impersonal y la versificación es libre. La impersonalidad de los poemas los hace alejarse del estilo subjetivo asociado a la poesía lírica y podría estar vinculado a la objetivación fotográfica. También se relaciona con los procedimientos empleados por el poeta en la construcción de su voz, que tal como señala Kay en Circuito cerrado, corresponde a una cita $^{3}$, la de la editorial del diario, una emisión a la vez anónima y colectiva (23), que surge a partir del ejercicio del rewriting, "práctica redaccional por la que la noticia es reescrita no solo una, sino múltiples veces" (24) [cursivas en el original], a través de técnicas entre las que se cuentan interpolaciones, rellenos, cortes, reformulaciones, reagrupaciones, montaje, etc.,

3 En una nota al pie en Circuito cerrado, Kay se distancia también de la antipoesía al declarar: "La antipoesía también cita, pero al lenguaje oral. [...] No obstante, citar lo escrito es citar otra cosa que el lugar común; lo que se confabula y organiza como propiamente escritural es otro tipo de cristalización" (23). 
que no son visibles en la versión final (Circuito cerrado 24). Esta forma de escritura apela al inconsciente colectivo por sus alusiones, sobreentendidos, perífrasis y el uso de lo tácito, entre otras figuras retóricas (Circuito cerrado 24), y con ello subvierte la lectura del lenguaje oficial ${ }^{4}$ (Circuito cerrado, 25). El efecto que se produce es por una parte un trastocamiento de la temporalidad entendida como linealidad, y por otra, una desindividualización. Respecto a la interrupción de la temporalidad, este es el resultado de la historia entendida benjaminianamente como catástrofe. Kay escribe: "El verso cita al lenguaje periódico y, presentado al pie de la letra, lo actualiza en su futuro. No se significa sino que se conjura, sin que sea mentado, lo venidero. [-] Catástrofe permanente, que siempre ya ha ocurrido" (Circuito cerrado 27) [cursivas en el original]. La desindividualización, por su parte, se hace evidente desde el título en el poema "He has no self to express"':

Nada ha cambiado después de su partida

(Como en la fábula de los dos jóvenes

Sus dos alazanes y sus dos lirios

Son todos en cierto sentido uno)

La frágil sonrisa sobre la placa sensible

Es prueba suficiente de la eternidad. (31)

En este poema el hablante declara sobre un tercero, que no tiene un "yo" para expresar. El poema parece describir una imagen, en la que un sujeto sonríe. Esta efigie se inscribe en una placa fotográfica y sirve como prueba de eternidad. Los tiempos se equiparan, de manera que el tiempo después de la partida del sujeto aludido, es el mismo que el de la fotografía, ya que todo parece haberse congelado: "Nada ha cambiado después de su partida" (31).

En "Fuera de alcance" se habla de fotografías postales en tercera persona. Un personaje distinto al hablante encuentra cuatro postales con imágenes del matadero. Lo que el poema destaca es la materialidad de ellas, su diferencia de tamaño y el hecho de que una de ellas ha sido retocada:

Encontró cuatro versiones similares

de tarjeta postal (c/u de tamaño diferente)

de una toma del interior

4 Kay escribe esta pregunta en una nota al pie sobre las Variaciones ornamentales, que alude al efecto de técnicas como el rewriting y su consecuente impersonalización y su vinculación con la historia: “¿no es la herida que abriera en mí la inhumanidad nazi, la antena que permitió detectar los desiertos artificiales de la nación en la alta retórica periodística de la era UP, guerra civil soterrada?" (Circuito cerrado 11)

5 En el poema "Camuflaje" de Deep Freeze también encontramos de manera explícita este anulamiento del yo en el verso final: "Rieles en un aeródromo abandonado:/el neón le da a la mano armada/la apariencia de una arabesco/ El fuego purificador arde/ para quemar los últimos vestigios./ Efectuada la ceremonia/ se estrecharon la mano y luego/ se confundieron en un abrazo./ No es el yo quien habla" (93) 


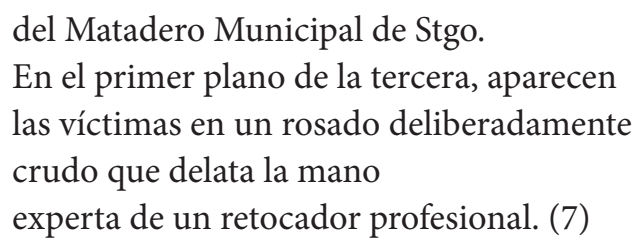

Aquí la tarjeta postal retocada a mano es una fotografía mediada por la pintura, que la ha intervenido, causando la impresión del observador. Este es capaz de distinguir los distintos planos y capas de la imagen, y la rosada carne animal, en primer plano. Pero ¿qué es lo que está fuera de alcance? ¿será que las sucesivas mediaciones producen de forma escalada un distanciamiento, que culmina con la intervención de la mano que la pinta? La textura pictórica tiene una materialidad distinta a la de la imagen fotográfica y se diferencia de ésta en que su génesis no es automática-como dice de la fotografía André Bazin-sino que está moldeada por el movimiento de la mano (un cuerpo) que la hace posible.

En el poema "Entrar en materia (o Álbum de familia)" la mediación de la fotografía y su intervención de la temporalidad se ven paso a paso. Allí leemos tres estrofas que retratan momentos distintos del proceso fotográfíco:

En el abismo -solo

Una extensión en la perspectiva -la pose

El enésimo calco del esquema.

De este monumento en forma rectangular

Manchas de sepia en un campo devastado

Pasaron a la posteridad, envejecidas.

El recuerdo que no puede llegar

A su término: lágrimas prehistóricas

Captadas en el lente de la cámara oscura. (22)

En la primera estrofa, se nos habla de la pose y de un punto de vista que produce el efecto de un abismo. Allí la pose es una reproducción de algo que se repite, que se calca, probablemente, algún gesto. Este es el momento de la toma fotográfica, del Spectrum según Roland Barthes. En la segunda estrofa se hace referencia a la fotografía como materialidad. Se la define como un monumento con una forma y color determinados, que sufre en sí misma el paso del tiempo. Se trata aquí del momento del Spectator, o en otras palabras, de la observación de la fotografía. En la tercera estrofa, está el punctum: las lágrimas detenidas en el papel, en la paradoja del tiempo pasado y detenido, como las que Juan Luis Martínez describirá en La nueva novela, de 1977, con epígrafe de Ezra Pound: "Eyes that I saw in tears" (140). 
Los dos próximos poemas que revisaré tienen en común una relación con la historia. Como el resto del libro, los poemas impersonales parecen fragmentarios y herméticos. En "Reconstrucción de una época" se habla de un permiso municipal que permitió el registro fotográfico de algo - no tenemos muy claro de qué- lo que se transforma en una práctica consecutiva en el tiempo, que permite conservar la imagen para la posteridad:

Con el beneplácito de la indulgencia edilicia

El mundo exterior pasó a la historia;

Respetuosos de la tradición

Algunos aficionados siguieron usando el veneno.

Eso no es un accidente: los nombres propios

Ya no anticipan las diferencias visuales.

Habrá que fijar con plomo los seres movedizos

Que se deslizan por el paisaje, risueños. (23)

La fotografía aparece consignada como veneno, aunque también pudiera pensársela como fármacon derrideano (102), es decir, como veneno y remedio al mismo tiempo, ya que este veneno produce seres movedizos pero sonrientes. Una vez inaugurada la práctica de la fotografía, su ejercicio se siguió implementando a lo largo del tiempo, incluso por fotógrafos aficionados. En el poema la fotografía realiza su operación sobre el tiempo a través de la sincronicidad de temporalidades. Esto se logra a partir de la inscripción o la fijación, es decir, a partir del paradójico congelamiento del movimiento, el cual se realiza con un elemento material: el plomo.

El poema "Clarity is not enough" parece una continuación del anterior, aunque no de manera consecutiva, ya que ambos están separados por algunas páginas. En él, los fotógrafos continúan su labor de registro para la posteridad, con cuidado y sensatez, retratando sujetos y monumentos. Pero tal como lo advierte el título, que reza que la claridad no es suficiente, la labor fotográfica, en lugar de generar evidencias y certezas, provoca otra paradoja: construye un espectáculo del que debemos sospechar, ya que lo que se reproduce son procesos congelados, que no terminan de ocurrir ante el lente de la cámara:

Quienes tienen a su cargo

Tan delicada como responsable misión

Parten a los alrededores

a escrutar los rostros

A remozar los monumentos sumergidos

En los años, a sospechar de todo

$Y$ de cada uno

El placer de vivir en un espectáculo 


\section{reproduciendo \\ La incertidumbre \\ De un hecho inconcluso (30)}

En la lectura atenta de este poemario, podemos encontrar algunos de los primeros síntomas del pensamiento fotográfico de Kay. En ellos está el carácter medial de la fotografía, que se filtra con su materialidad tanto en la pintura como en la escritura. También está su intervención como paradoja temporal, que se verifica en el congelamiento del instante, y en la creación de una sincronía entre lo que se fija y lo que deviene. De allí a la imagen en movimiento hay un solo paso. Por eso es interesante la referencia -aunque fotográfica- al cine reproducido a través de ondas electromagnéticas en Variaciones ornamentales. El reverso de ese interés es el que Kay propone en Deep Freeze, ese congelamiento profundo de la escultura que ilustra la portada del libro con la escultura de Ifigenia de Rodin: materia inmóvil que representa un cuerpo en movimiento.

En el Laocoonte (1776) Gotthold Ephraim Lessing hace una distinción entre poesía y plástica. Para Lessing la pintura es un arte espacial, mientras que la poesía puede representar las acciones en el tiempo. De este modo, el intento de la escultura o la pintura por representar las cosas en su devenir temporal -en otras palabras, en movimiento-, sería vano, a juicio de Lessing, ya que esta sería tarea de la poesía. En el poema V de Deep Freeze, Kay alude al problema del movimiento y su elaboración escultórica, la cual vincula con la muerte:
Empuja su carromato, la lenta locomoción de su sombra
se hunde:
de un transcurso la huella digital, así de un héroe inconclusa
la estatua se estanca
la filigrana del aire se espesa, los maderos tumefactos
exhudan una agridura -hablan del finado. (52)

Lessing no pudo extender su reflexión a los medios de reproductibilidad técnica, sin embargo, en la fotografía se verifica esta detención, este congelamiento, mientras que en el cine la imagen en movimiento surge como fruto de una paradoja cognitiva: imágenes fijas que denotan el movimiento gracias a la presencia de un observador. En Deep Freeze hay varios poemas que aluden a la imagen en movimiento, por ejemplo, "Plano secuencia", un poema en segunda persona singular, dirigido a Raúl Ruiz, que remite a sus películas, como por ejemplo a Tres tristes tigres (1968):

Claro, Raúl, hay que irse por las ramas

mirar pal otro lao, como si nada,

buscar las cinco patas del gato 
o subirse a una micro para bajarse una cuadra

más allá y partir a cualquier parte

[...]

No te irías por la tangente, robándote la película

si no te centraras en la ilusión

que en el bolero baila voy a morir sin tu amor,

si no estuvieras cachando por el espejo

lo que está pasando por otro lao, o cuando te adueñas

de un prostíbulo para acelerar la droga del ansia

y abusas de la noche con el chancho y el ajo, con las idas

y venidas entre las distintas piezas de una misma urbe

y las interminables escaleras de los bares

hasta llegar a la evidencia del vómito,

si no recopilaras esas horas en vano

en un alma vanidosa, en un desvelo de amor,

el adiós a los circuitos de la muerte, a las letrinas

infestadas de garabatos, al olor de carburo y fierro

en la Estación Mapocho, o al crepitar eléctrico de las medias

de la hembra que se desnuda, te sería fácil,

como botar una entrada al cine [...] (40-41)

En el poema el plano secuencia al que se refiere el título es una larga toma que registra acciones que se van acumulando en el tiempo, una tras otra, casi sin transiciones. Esta secuencia se emite sin cortes, o con los cortes mínimos, representados en el poema por el punto seguido. Así, el cine remite al movimiento a través del plano secuencia, que implica un despliegue de las acciones - mínimas en el caso de Ruiz, de allí que el hablante del poema hable de "horas en vano"- se realiza de manera indirecta en el tiempo, y no a través del corte que implica el montaje.

En "A little step" Kay registra el espectáculo masivo transmitido por televisión, de la llegada del hombre a la luna:

Nos habíamos sentado a presenciar

la conquista espacial -mas el espectáculo

éramos los televidentes, reliquias herméticas

flotando en sus sillones por el espacio

de los sputkniks desorbitados.

En la últimas células vivas sentíamos aún, estatuas de Lot, la venda de luz

con la que el ojo mágico

nos iba momificando, inhumándonos

en la tierra, cuerpo celeste sin importancia. (73) 
Se produce en el poema una transmutación entre los espectadores y el espectáculo. La puesta en escena y el "ojo mágico" del televisor convierte paulatinamente a los espectadores en estatuas de sal o en momias inmóviles, a pesar de la imagen en movimiento del espacio, las naves sputnik y el astro lunar. En cierto sentido, Kay se refiere al impacto negativo de los medios masivos en la construcción de un espectador pasivo, metaforizado en la ausencia de movimiento de la momia o estatua. Del mismo modo, se genera un contrapunto entre lo que sucede en pantalla y lo que ocurre en la tierra, ese "cuerpo celeste sin importancia", como si las temporalidades del universo fueran distintas y distantes de la temporalidad humana: la historia, que según Kay se presenta siempre en forma de catástrofe, es invisible a la temporalidad del universo, sublimizada por la presencia del registro televisivo. Esa temporalidad no humana del universo está también consignada en el tiempo lento que demora en crecer el musgo en una tabla de madera en "Cierre":

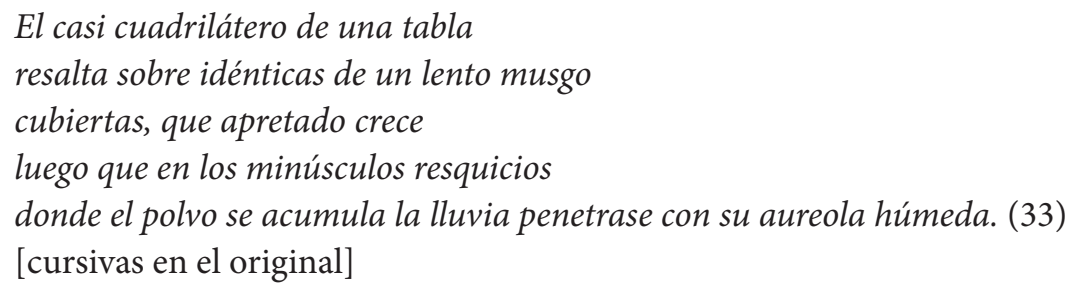

Esa temporalidad lenta en que el musgo crece a causa de la lluvia entre los surcos de la madera, se enfrenta a la intervención de la cultura, la temporalidad humana y la historia a través de los afiches despegados que como un decollage cubren el muro:
[...] en tanto que en las restantes las estampas
verdipardas y amarillo oxidadas
del liquen se despliegan voraces entre las reliquias de unos afiches cuyas interruptas letras se unen
con incongruentes campos de pintura. (33) [cursivas en el original]

Naturaleza y cultura se unen en este poema, que a modo de palimpsesto o capa geológica, acumula distintas temporalidades, tanto humanas como no humanas. Hay otras dos experiencias temporales que se visualizan en los poemas de Deep Freeze: la temporalidad del instante y la del recuerdo o la memoria, ambos mediados ya sea por la pintura o la fotografía. En el poema IV Kay escribe:

Solamente ese por supuesto como de zapatos recién lustrados demora al transeúnte en el mecanismo vencido de lo remoto - la acuarela 
ferruginosa de las hortensias lo realzano la distancia que media entre las pupilas

y la vidriera donde ya se quisieran atrapar sólo se franquea a cambio de un regreso para ganar la distorsión del rostro

que abruptamente se nos aparece: único reducto de lo conocido: oferta de escaparate. (50)

Este poema urbano da cuenta de una escena cotidiana: la mirada fugaz de un transeúnte hacia una vitrina, en la que ve su rostro reflejado y distorsionado. Ya no es el poema baudeleriano de amor a primera y última vista en el metro, sino que una mirada rápida e instantánea sobre imágenes que se superponen y coinciden, generando un extrañamiento en el sujeto: un vidrio que refleja y detrás, una mercancía que se oferta. La mención a la acuarela azulada remite a una tonalidad particular, pero también al trazo rápido de la técnica de la acuarela, que a diferencia del óleo puede ser traslúcida y de secado casi instantáneo. Así, todo el poema remite a la temporalidad del instante.

El poema VIII comienza así:

El trayecto del lápiz sobre el papel recupera

los desperdicios: sueño en que dejáramos

la Kodak, la arrebujada muda

en la arena: una radio a pila disfraza

los puntos cardinales -los obeliscos

de los cuerpos se ofrecen al olvido

igual que un recuerdo. ¿Dónde estamos? (54)

Se trata aquí del registro de una experiencia recuperada a través de la escritura a mano y la memoria, despojada del registro maquínico de la máquina fotográfica, que fue dejada sobre la arena y por ello, expuesta al olvido. La pregunta que cierra el verso remite a la incertidumbre propia de los vacíos que deja la memoria.

En definitiva, el carácter medial o la medialidad es central en la escritura de Ronald Kay, ya sea en los poemas de Variaciones ornamentales, Deep Freeze o Del espacio de acá. El medio opera como una especie de de tamiz que transforma la escritura en su dimensión temporal y su modo de dar cuenta del movimiento. Es su escritura fotográfica se evidencia el carácter material de las fotografías como objetos manipulables e intervenibles, mudos y detenidos, capaces de generar una disrupción del tiempo lineal. En Del espacio de acá Kay describe en un tono más conceptual estas transformaciones producidas por el aparato fotográfico en el continente americano, haciendo evidente que las transformaciones mediales y técnicas tienen consecuencias en el plano estético, filosófico y geopolítico, ya sea a partir de la catástrofe de la colonización, o del Golpe militar y la dictadura. En sus poemas sobre imágenes en movimiento y otras mediaciones (cinematográficas o televisivas), Kay apunta a 
ciertos procedimientos específicos como el plano secuencia o al fenómeno cultural que producen los medios masivos. Estos medios implican una transformación de la temporalidad y la escala espacial, y abren la posibilidad de vislumbrar dimensiones temporales no humanas que corren paralelas al tiempo histórico, pero no se agotan en él, planteando así interrogantes sobre la experiencia humana de la temporalidad, el instante y la memoria. Circuito cerrado, como su nombre lo indica, es un sistema que se observa a sí mismo, de modo que entrega claves sobre su escritura mediada desde Variaciones ornamentales hasta sus inéditos, publicados a partir del 2011.

\section{Referencias}

Barthes, Roland. La cámara lúcida. Trad. Joaquim Sala-Sanahuja. Barcelona, Paidós, 1989.

Benjamin, Walter. “Pequeña historia de la fotografía”. Discursos interrumpidos I. Trad. Jesús Aguirre. Buenos Aires, Taurus, 1989.

Bazin, André. "Ontología de la imagen fotográfica”. ¿Qué es el cine? 1. Madrid, Rialp, 2004, pp. 28-29.

Derrida, Jacques. La diseminación. Caracas y Madrid, Editorial Fundamentos, 1997. Flusser, Vilém. Hacia una filosofía de la fotografía. México, Trillas, 1990.

---. El París de Baudelaire. Trad. Mariana Dimópulus. Buenos Aires, Eterna Cadencia, 2012.

Lessing, Gotthold Ephraim. Laocoonte. Ed. Antonio Molina Flores. Madrid, Editorial Tecnos, 2015.

Martínez, Juan Luis. La nueva novela. Santiago de Chile, Ediciones Archivo, 1985.

Kay, Ronald. Variaciones ornamentales. Made in Germany. Santiago de Chile, Ediciones Estudios Humanísticos, 1979.

---. Del espacio de acá. Santiago de Chile, Ediciones Metales Pesados, 1980.

---. Deep Freeze. Los inéditos de la década de los 60. Santiago de Chile, Ediciones Nómade, 2000.

---. Circuito Cerrado. Los inéditos de la década de los 60, glosas. Santiago de Chile, Ediciones Nómade y Ediciones Calabaza del Diablo, 2011.

Kittler A., Friedrich. Gramophone, Film, Typewriter. Standford, UP, 1999.

Ranciére, Jacques. El espectador emancipado. Trad. Ariel Dillon. Buenos Aires, Ediciones Manantial, 2011.

Sontag, Susan. Sobre la fotografía. Trad. Carlos Gardini. Buenos Aires, Alfaguara, 2005. 